Revista de Derecho

\title{
La politicidad inmanente del arte y el derecho
}

The immanent politicity of Art and Law

\section{Diego Zambrano Álvarez}

Universidad Internacional del Ecuador

diegozambrano03@gmail.com

DOI: https://doi.org/10.32719/26312484.2019.31.5

Fecha de recepción: 4 de marzo de 2018

Fecha de aprobación: 26 de febrero de 2019 


\section{RESUMEN}

En este artículo, el autor pretende demostrar la inmanente función política del arte y del derecho como estructuras creadoras de un mundo artificial diseñado por las élites para su control y beneficio. En esta línea, y a manera de hipótesis se sostiene que el derecho y el arte latinoamericano han entrado en una lógica de emancipación estética y jurídica a partir de la reivindicación de su identidad popular y mestiza capaz de establecer una visión única y distinta al constitucionalismo clásico europeo, a partir del cual se busca hacer frente a los desafíos de una posmodernidad depredadora, consumista y globalizada.

PALABRAS CLAVE: arte, constitucionalismo, Latinoamérica, estética, posmodernidad.

\section{ABSTRACT}

In this article, the author pretends to show, the political function of art and law, like creation of an artificial world designed by elites for their control and benefit. However, it is argued that the Latin American law and art have entered in a new version, born than its own identity, juridical and esthetics forms, with which pretends develop a new version of constitutionalism, since its culture baroque, popular and mixed between the European and native matrix. With all this, the Latin-American countries pretends overcome the challenges of postmodernity predatory, consumerist and globalized.

KEYWORDS: Art, constitutionalism, Latin America, esthetic, postmodernity.

\section{INTRODUCCIÓN}

T a estética, como objeto de reflexión teórica, tiene como ascendiente directo a La denominada crítica del gusto. ${ }^{1}$ Kant en su Crítica del juicio, ${ }^{2}$ para muchos la obra pionera en la consolidación de la estética como disciplina filosófica debido a su profundidad conceptual y expresiva, contó con una impronta psicologista de la que progresivamente se ha emancipado y a la que se ha añadido un componente de análisis social y, como tal, político. Así, en su Ensayo sobre Wagner ${ }^{3}$ Adorno analiza la forma

1. En filosofía se habla de crítica como posibilidad de conocimiento de la razón pura o práctica, por ejemplo; y no como juzgamiento, según su uso común.

2. Immanuel Kant, Crítica del juicio (Buenos Aires: Biblioteca Universal, 2003).

3. Theodor Adorno, Ensayo sobre Wagner (Madrid: Akal, 2008). 
en la que el gran creador del drama musical imprime un contenido político revolucionario en obras de la talla del Anillo del Nibelungo, cuyo contenido filosófico descansa entre el materialismo de Feuerbach y el pesimismo de Schopenhauer; y su dialéctica entre la pulsión que imprime voluntad y la racionalidad dispuesta en su representación del mundo y su devenir. ${ }^{4}$

Hannah Arendt ${ }^{5}$ encontró en la Crítica del juicio de Kant al teórico político que no halló en sus dos críticas precedentes, ${ }^{6}$ en tránsito hacia sus Fundamentos sobre la metafísica de las costumbres, que quizá es su obra más jurídica, donde esboza el concepto de imperativo categórico y la exigencia de tratar a los seres humanos como fines en sí mismo y no como medios, para la consecución de fines ajenos. La propuesta estética y política kantiana deviene en una síntesis entre el racionalismo de la razón pura, y el empirismo de la razón práctica. Por su parte, el arte contendría un nivel de sociabilidad tan importante por ser capaz de proyectar lo que ocurre en el interior del artista a fin de compartirlo y resignificarlo por otros una y otra vez. En consonancia, la valoración que estos hacen de la obra, como un consenso sobre su valía, nos introduce en discusiones objetivas sobre la técnica empleada y subjetivas sobre el poder expresivo y conmovedor, lo que implica un debate fenomenológico que directamente nos remite a Husserl. ${ }^{7}$

En su ópera prima, Nietzsche ${ }^{8}$ encontró en el arte la característica definitoria de la naturaleza humana, que consiste en la lucha intestina entre lo dionisíaco y lo apolíneo, posición que fue refrendada por el psicoanálisis, bajo el concepto de pulsión de vida, que se relaciona con el instinto de conservación y goce, y la pulsión de muerte, que constituye tendencias autodestructivas. ${ }^{9}$ En la mitología griega, Apolo representa la intelectualidad, la técnica y la civilización. Contrariamente, Dionisio representa el disfrute carnal, el exceso y los placeres; es dios del vino y la embriaguez. Así, lo racional y lo instintivo (la representación y la voluntad; el ello y el superyó) serían las dos caras de una misma moneda, que se materializa en un arte trágico lleno de emoción,

4. Arthur Schopenhauer, El mundo como voluntad y representación (Madrid: Alianza Editorial, 2015).

5. Cristina Sánchez, Estar (políticamente) en el mundo (Madrid: Batiscafo, 2015).

6. Nos referimos a la Crítica de la Razón Pura y a la Crítica de la razón práctica.

7. La fenomenología propuesta por Husserl toma su nombre de la distinción kantiana entre fenómeno y nóumeno, aplicado al lenguaje y a la representación. El fenómeno es lo que se muestra y es capaz de ser percibido por los sentidos; el nóumeno o la cosa en sí constituye aquella experiencia imposible para el ser humano, o en Husserl para el receptor del mensaje porque no puede saber la intencionalidad real con la que se emiten enunciados comunicacionales. Ver Edmund Husserl, Fenomenología de la conciencia inmanente del tiempo (Buenos Aires: Prometeo, 2014).

8. Friedrich Nietzsche, El nacimiento de la tragedia (México: Grupo Editorial Tomo, 2014).

9. Sigmund Freud, Esquema de psicoanálisis (Madrid: Alianza Editorial, 2016). 
valores y simbolismo, que desde lo sagrado y cultural descienden hacia lo político y lo jurídico. ${ }^{10}$

Esta contribución pretende establecer algunas relaciones entre el arte y la política, como variables independientes y definitorias para las estructuras jurídicas. Para ello, manejaremos tres hipótesis principales. La primera, alude a los sectores económicamente dominantes que son los instauradores de las estructuras culturales, que definen una estética, que fundamentan discursivamente un modelo social y un sistema de valores. La segunda hipótesis refiere a la función política del arte, a partir del dominio del imaginario social por medio de la acción comunicativa. ${ }^{11}$ Finalmente, como tercera hipótesis, sostendré que en América Latina las mismas estructuras artísticas y jurídicas opresivas han sido tomadas como herramientas emancipadoras frente a una posmodernidad degradada, consumista y depredadora.

\section{DOMINIO ECONÓMICO Y ESTRUCTURA CULTURAL}

Sostendremos que la violencia original, generalmente proveniente de la mitología, constituye el elemento fundacional de toda sociedad política. Hegel recurre a la metáfora de la dialéctica del amo y el esclavo para explicar esta lucha arquetípica por el poder. ${ }^{12}$ Para el autor, la historia parte del encuentro entre dos personas que se entienden diferentes y de esta forma reafirman su subjetividad. Al reivindicar tal individualidad, ambas autoconciencias desean que el otro le reconozca como amo y se le someta. No obstante, y dado que ambas desean lo mismo, entablan una guerra a muerte, en la que triunfa aquel en quien prima la voluntad porque no se detiene y está dispuesto a arriesgar la vida porque valora más su libertad.

Aquel que valora más su vida, se somete para conservarla, pero asume el rol de siervo que conlleva la ejecución de los trabajos que el amo evita realizar por fatiga o por percibirlos degradantes, pero que son indispensables para la conservación de la vida. Se establece, entonces, una contradicción dialéctica que enfrenta a la idea, que proviene del amo, y la ejecución de la idea por parte del esclavo, quien al transformar la materia, altera el mundo hasta convertirlo en un artificio. ${ }^{13}$ El esclavo crea herramientas para mejorar su capacidad para satisfacer necesidades vitales; no obstante, la

10. Diana Cherne, La creencia y el psicoanálisis (México: Fondo de Cultura Económica, 2006).

11. Jürgen Habermas, Teoría de la acción comunicativa (Madrid: Cátedra, 1994).

12. G. W. F. Hegel, Fenomenología del espíritu (México: Fondo de Cultura Económica, 2015).

13. El marxismo comparte el punto de partida, no obstante, para Hegel es la idea la que transforma el mundo; para Marx, es el trabajador quien, al transformar la materia, escribe la historia. Jacques D'Hondt, De Hegel a Marx (Buenos Aires: Amorrortu, 1972). 
materia transformada adquiere significación cultural que desarrolla formas particulares de arquitectura, gastronomía o danza, hasta alcanzar los ámbitos más abstractos en el arte e institucionales en el derecho.

En la modernidad, la fábrica edificó la ciudad, urbanizó la cotidianidad y determinó los hábitos en el uso del tiempo, en función de su demanda de mano de obra. Luz eléctrica, alcantarillado, escuela, parque, bar y biblioteca construyeron un mundo artificial, que define nuestra forma de vida. El mundo transformado a partir del concepto impuesto por el amo, le dio un orden al mundo para entenderlo, a partir de patrones prefabricados a la luz de las formas de producción de mercancías, a partir de las cuales filtramos y significamos la información que percibimos. ${ }^{14} \mathrm{La}$ instauración de un mundo simbólico desde una centralidad hegemónica crea una identidad cultural determinada, que instaura superestructuras artísticas y morales, creadoras de nichos de poder, que son refrendadas por las autoridades por medio del derecho. ${ }^{15}$

La idea se impone desde centralidades hegemónicas y define lo que ha de reconocerse como cultura, arte o derecho, diferenciándose del folclor, la artesanía, y los usos y costumbres. La oficialidad de la idea norma en actividades naturales como comer, vestir, procrear, trabajar, consumir, hablar, escribir y divertirse; normativiza la vida según manuales de urbanidad, academias de la lengua, conservatorios, registros civiles, iglesias, ministerios de cultura; todas ellas, estructuras de autoelogio para las clases dominantes y paradigmas de civilización. Así, la barbarie se mide según la cercanía o alejamiento que una persona o grupo tengan en función de la cultura hegemónica, que es la que determina la relación desarrollo/subdesarrollo. ${ }^{16}$

La civilización se opone a la barbarie y establece una jerarquía en lo político, estético y jurídico. ${ }^{17}$ En el Facundo, obra de enorme significación política y jurídica para el republicanismo latinoamericano, Domingo Faustino Sarmiento vio en Francia un refinamiento digno de imitar. ${ }^{18}$ En contrasentido, vio en el nativo lo primitivo y rústico, que por su bien debe ser erradicado. De esta manera, la cultura dominante traza una línea del tiempo y nos clasifica entre desarrollados y subdesarrollados, imponiéndole a la periferia el deber de homologación, por medio de prácticas enajenantes, por

14. Michel Foucault, Las palabras y las cosas (Buenos Aires: Siglo XXI Editores, 1968).

15. Max Horkheimer y Theodor Adorno, Dialéctica de la Ilustración (Madrid: Trotta, 2006).

16. Stefan Gandler, Marxismo crítico en México: Adolfo Sánchez Vásquez y Bolívar Echeverría (México: Fondo de Cultura Económica, 2015).

17. Kant jerarquiza el gusto entre lo bello y lo sublime. Lo sublime sería aquello que produce alegría y terror como la naturaleza, madre proveedora e indomable; y lo bello como aquello que produce agrado. Para Kant, lo sublime conmueve, en tanto que lo bello agrada.

18. Nótese la influencia neoclásica en la arquitectura de edificios públicos y teatros construidos en América Latina a inicios de la etapa republicana. 
contrarias a sus realidades sociales. ${ }^{19} \mathrm{El}$ dominio simbólico eurocéntrico concede al sector hegemónico la capacidad para separar lo moral y lo inmoral, lo bello y lo feo, lo jurídico y lo antijurídico; relación de la que surge la inicial dependencia entre ética y estética ${ }^{20}$ que hizo del arte una herramienta proselitista, como ocurrió con la escuela quiteña y cuzqueña del siglo XVII o el cine alemán del Tercer Reich.

En sus orígenes, el arte tuvo propósitos no necesariamente ornamentales, pero determinantes para definir una época. El arte rupestre perseguía propósitos religiosos e informativos sobre el territorio. Las figuras planas del arte egipcio transmitían conocimientos científicos y rituales; el románico comparta tal simplicidad con un objetivo religioso. Su sofisticación mediante la abundancia de detalles fue el germen del barroco, ${ }^{21}$ que es el estilo característico del arte colonial de América Latina, a partir del cual surgió una expresión cultural mestiza que nos es definitoria.

El barroco ${ }^{22}$ estuvo dominado por el neoplatonismo de San Agustín y la filosofía utópica de Moro, Campanella ${ }^{23}$ y Bacon; en ambos casos, fue Dios el centro de interés filosófico y artístico; y, como tal, fue determinante en el dominio del ius-naturalismo teológico como corriente dominante dentro del pensamiento jurídico. ${ }^{24}$ La decadencia del barroco dio paso al rococó, que llevó la abundancia de detalles a los interiores, precisamente cuando el poder dominante dejó de buscar respuestas en el cielo y vio en su vida privada un refugio y la oportunidad de demostrar su poder y estatus. Esta expresión artística coincidió con el modernismo nacido de una burguesía adinerada, que redujo el conocimiento jurídico a lo civil y penal a fin de garantizar la propiedad, descrita por Locke como derecho natural. ${ }^{25}$

19. Sartre vio en el demócrata a un enemigo para los judíos. Aunque se opusieron a su eliminación física, propuso su homologación, que implicaba su eliminación como pueblo. Jean-Paul Sartre, Reflexiones sobre la cuestión judia (Buenos Aires: Penguin Randon House, 2015).

20. Gerard Vilar, "Ética y estética", en Estética, editada por Francisca Pérez (Madrid: Tecnos, 2013), $237-61$.

21. E. H. Gombrich, La historia del arte (Nueva York: Phaidon, 2014).

22. El barroco como expresión estética en la que los adornos llegan a tener tal complejidad en sus formas que alcanzan autonomía respecto a la estructura adornada. El barroco genera una visión de movimiento o danza, por lo que puede ser visto como un arte lleno de ambigüedades, extravagancias y contradicciones. Pierre Cabanne et al., El Barroco (Barcelona: Larousse, 2007).

23. En La Ciudad del sol, Campanella sugiere un gobierno concentrado en una autoridad religiosa llamada Hoh, apoyada por un triunviro (Pon, Sin y Mor) también religioso. Uno se encargaba del poder, otro de la sabiduría y otro del amor. El aprendizaje se apoyaba en las obras de arte que permitían comprender pasajes del Evangelio a personas analfabetas, que eran la mayoría de la población. Esta estrategia se implementó en América y explica la importancia de imágenes consideradas sagradas. Tommaso Campanella, La ciudad del sol (México: Grupo Editorial Tomo, 2015).

24. Edgar Bodenheimer, Teoría del derecho (México: Fondo de Cultura Económica, 2007), 153-97.

25. John Locke, Segundo Tratado sobre el Gobierno Civil (Buenos Aires: Alianza Editorial, 1998). 
Paralelamente al barroquismo español, en Francia predominó el neoclacisismo, que amplificó una visión racionalista de la existencia, y como tal rescató la filosofía política y estética de la Grecia clásica, representada en su arquitectura, escultura, literatura e inclusive sus mecanismos democráticos, equiparando el hombre libre al hombre burgués. Desde esta perspectiva, no resulta extraño que en el Siglo de las Luces, la escuela de la exégesis y la jurisprudencia de conceptos sean las corrientes predominantes. ${ }^{26} \mathrm{Se}$ aboga por la interpretación literal del texto legal, garantizándose así la omnipresencia de la burguesía en todo aspecto, porque la ley era elaborada por ciudadanos, entiéndase varones, propietarios, profesionales o casados; es decir, por burgueses, que al equiparar el concepto de voluntad general de Rousseau al de ley, trasladó su dominio económico hacia las estructuras ideales y simbólicas, que son tierra fértil para la política y el derecho.

El idealismo alemán, dominante en la Prusia del siglo XVIII, encontró notas fecundas en el romanticismo de Beethoven, Schumann y Schubert, que reivindicó la autoconsciencia germana nacida de la tradición. El derecho amplificó este pensamiento e hizo del historicismo la corriente ius-filosófica dominante de la época. ${ }^{27}$ No obstante, se resguardó el poder de las élites al conceder al legislador la posibilidad de determinar cuál es la tradición oficial, cuáles deben erradicarse, y qué prácticas son permitidas por inocuas.

En la modernidad tardía, cuando ciencia y técnica ocuparon los espacios centrales de interés, aparecieron tendencias vanguardistas, tanto en el derecho como en el arte. La teoría de la relatividad del tiempo de Einstein fue motor para la fenomenología de Husserl ${ }^{28}$ y para el existencialismo de Heidegger. Estas propuestas científico-filosóficas marcaron el inicio de la posmodernidad, y del arte abstracto y conceptual que dominan las corrientes estéticas contemporáneas. La relatividad y el psicoanálisis inspiraron la genialidad de Dalí y tomaron formas surrealistas, germinando así una vanguardia que impregnó a la totalidad de las superestructuras.

El derecho acompañó la tendencia, con el auxilio de propuestas conductistas y de elección racional, tomadas de las ciencias políticas. ${ }^{29}$ Estas tendencias influyeron en los teóricos defensores de la Escuela del Derecho Libre y del realismo, en sus dos principales versiones. El realismo norteamericano pretendió predecir las decisiones judiciales, mediante el análisis de los estados mentales del juez; así como el conductismo escandinavo que entendió al derecho vigente como la versión actualizada de

26. Andrés Botero, comp., Filosofia del Derecho (Medellín: Universidad de Medellín, 2012).

27. Manuel Atienza, Introducción al Derecho (México D. F.: Fontamara, 2007), 122-36.

28. Edmund Husserl, Fenomenología de la conciencia inmanente del tiempo (Buenos Aires: Prometeo, 2014).

29. Mario Bunge, Filosofia política (Barcelona: Gedisa, 2009): 201-55. 
una norma positiva cuyo alcance se completa por medio de la interpretación y alcance que le asigna el juez. ${ }^{30}$

Así, el ethos de una sociedad se articula a través del pensamiento filosófico que interpreta el mundo para (re)presentarlo y darlo a conocer por medio del discurso. El tipo de realidades discursivas, como actos del habla creadores de realidades intersubjetivas, será una herramienta a cargo del sector social y económicamente dominante, que al acaparar el discurso, conquista las estructuras ideológicas y estéticas. Luego, el sistema de valores universalizados e impuestos desde el centro hacia la periferia desarrollan un patrimonio simbólico que expresa un arte institucionalmente garantizado por el derecho, concede oficialidad y objetividad a una forma determinada de pensar, excluyendo a todas las demás. ${ }^{31}$

En definitiva, el sector dominante impone la agenda y las prioridades de cada época, con lo que marca el camino y el ritmo a seguir. La filosofía dominante, como sistema de interpretación de la totalidad de lo real, condiciona el gusto artístico y la ideología político-jurídica que se sostienen de la misma infraestructura económica; y con ello, el dominio del espacio material y simbólico que recrea al mundo a su imagen y semejanza, y define para todos el estilo de vida que ha de seguirse.

\section{PODER, ARTE Y DERECHO EN LA MODERNIDAD Y SU DECADENCIA}

La muerte de $\operatorname{Dios}^{32}$ dejó un vacío en la filosofía, en el arte y en el derecho. La necesidad de encontrar fundamentos a la existencia humana, desde lo humano, sin un camino hacia la salvación eterna, hizo que la razón tome el sitio de la divinidad y empiece a perseguir el conocimiento que le permita comprender al mundo. La modernidad nace con el método científico propuesto por Galilei, aunque sus antecedentes corresponden a Guillermo de Ockham y su navaja, ${ }^{33}$ que pretendía economizar el saber mediante formulaciones hipotéticas y causales, similares a las reglas jurídicas.

Filosóficamente, la modernidad se configuró sobre el debate entre el empirismo de Hume y el racionalismo de Descartes, lo que desembocó en un plan civilizatorio y epistemológico, con evidentes ramificaciones en el arte y el derecho. El empirismo inglés, con Locke como referente, aplicó el método inductivo para retomar la construc-

30. Alf Ross, Sobre el derecho y la justicia (Buenos Aires: Eudeba, 2011).

31. Carl Schmitt, La tiranía de los valores (Buenos Aires: Hydra, 2012).

32. Friedrich Nietzsche, Asi habló Zaratustra (Madrid: Edimat, 2007).

33. Jesús Antonio Pascual Esteban, Víctor Tirado e Ignacio Verdú, Historia de la filosofía (Barcelona: Marenostrum, 2008), 180-91. 
ción casuística, haciendo de la jurisprudencia la fuente principal para los sistemas del Common Law. El racionalismo cartesiano repercutió en el pensamiento ius-filosófico francés; y, vía España, en el latinoamericano. El racionalismo, que parte de verdades generales y evidentes al pensamiento, para llegar a nuevas verdades por caminos inferenciales, aplica un razonamiento deductivo que parte de normas generales a casos específicos; haciendo de la ley la fuente jurídica por antonomasia, y del silogismo, su método de aplicación. ${ }^{34}$

Para Europa continental y Latinoamérica, el pensamiento lógico-formalista estableció las condiciones para la propuesta positivista de Kelsen, ${ }^{35}$ mediante un sistema cerrado y piramidal que parte de la norma universal; y, como tal, la menos inteligible, para descender gradualmente hacia normas que pierden en generalidad lo que ganan en concreción, encadenando normas bajo relaciones género-especie. ${ }^{36}$

Desde la cultura, la modernidad asume un plan civilizatorio manifiesto en el arte renacentista que dirigió su atención a lo humano, la subjetividad y la contemplación estética del cuerpo y la naturaleza. Así, el movimiento revolucionario francés de 1789 retomó el arte neoclásico y la iconografía de la mitología griega para representar a la diosa razón y a Temis, diosa de la ley o diké, desde la estética de la mujer griega.

El plan civilizatorio moderno se caracteriza por buscar dominio sobre la naturaleza, desencantamiento del mundo, desarrollo técnico, globalización del mercado y el individualismo subjetivo ${ }^{37}$ de los ideales de libertad, igualdad y fraternidad. No obstante, en la posmodernidad estas promesas demuestran su decadencia, al degenerar sus dinámicas sociales, intelectuales, estéticas y jurídicas; asunto sobre el que me detendré en el último movimiento de esta contribución.

Para el siglo XVII, la modernidad latinoamericana fue barroca y mestiza. Su identidad surgió del indio de la ciudad que aprendió a hablar castellano y a realizar los oficios cotidianos, transformando la usanza ibérica como una estrategia de supervivencia $^{38}$ que fue tomando tintes de resistencia y dio lugar a una identidad distinta, híbrida, que conocemos como cultura popular definitoria de nuestra idiosincrasia. ${ }^{39}$ Las dinámicas sociales pasaron a teatralizarse porque aprendimos a representar una forma de vida, para ser aceptados, sin dejar de ser indígenas. El chulla quiteño, Don

34. André Robinet, El pensamiento europeo de Descartes a Kant (México: Fondo de Cultura Económica, 2014).

35. Hans Kelsen, Teoría pura del derecho (Buenos Aires: Eudeba, 2000).

36. Eduardo García Maynez, Introducción a la lógica jurídica (México D. F.: Fontamara, 2010).

37. Tzventan Todorov, El espíritu de la ilustración (Barcelona: Galaxia Gutenberg, 2008).

38. Según etnógrafos, la población indígena se habría reducido al 5,5\% entre 1519 y 1625 . Nicolás SánchezAlbornoz, Historia mínima de la población de América Latina (México: Turner, 2014), 56-78.

39. Bolívar Echeverría, Modernidad y blanquitud (México D. F.: Era, 2010). 
Evaristo o Cantinflas son manifestaciones gráficas de una cultura sincrética entre dos vertientes culturales superpuestas.

El conquistador dominó el mundo simbólico mediante la sustitución de deidades, logrando una transición desde Coatlicue, madre del Quetzalcóatl mesoamericano y señora de la muerte, a la Guadalupe del Tepeyac. Igualmente, la sustitución de templos indígenas por catedrales. Desde el arte, la exuberancia del barroco ${ }^{40}$ se mezcló con elementos nativos que mantuvieron el impacto visual necesario para demostrar poder en los tiempos de la Contrarreforma. Vinculado estéticamente al renacimiento, el barroco fue alejándose de su espiritualidad hasta convertirse en retórica política.

A partir del siglo XVII se experimentó un proceso de hibridación social y artística que se extendió a todos los aspectos de la vida. El indio citadino incorporó sutilmente elementos autóctonos en las imágenes católicas, creando una nueva visión del cristianismo. También el culto, el rito y la adoración de imágenes fueron modificados, tanto como la gastronomía, la fiesta, el dialecto y la música, que incorporó además tambores africanos llegados en barcos negreros.

En los siglos XX y XXI, autores como Lyotard ${ }^{41}$ nos hablan de una era posmoderna como una forma de superación de la modernidad. No compartimos tal posición $y$, por el contrario, sostenemos que actualmente vivimos el estado decadente de la modernidad, en la que los grandes relatos sucumben ante un exacerbado relativismo, la banalidad y el casuismo. Las promesas modernas de la técnica y de la industria en lugar de crear condiciones de mejoras al estilo de vida para las mayorías generaron miseria y exclusión, sin contar con la degradación de la naturaleza en nombre de un modelo consumista de desarrollo. ${ }^{42}$

Desde la orilla jurídica, la degradación posmoderna también ha alcanzado manifestaciones importantes. El giro lingüístico que dio la filosofía a mediados del siglo XX llevó a autores como Russel1 ${ }^{43}$ a dedicarse al estudio atómico del lenguaje, es decir, a la palabra como unidad mínima de comunicación, así como al positivismo ideológico a cerrar su campo de estudio en la regla como molécula de toda normatividad. El giro lingüístico del derecho deja de lado la complejidad de derecho como un sistema bifronte entre la realidad social material y la realidad normativa metafísica, ${ }^{44}$ entre las que se establecen relaciones de reciprocidad e interdependencia; para mini-

40. Pierre Cabanne, Joaquín Soler y Marta Masafred, El Barroco (Barcelona: Larousse, 2007).

41. Jean-Françoise Lyotard, La condición posmoderna (Buenos Aires: Planeta, 1990).

42. Erich Fromm, Ética y politica (Barcelona: Paidós, 2004).

43. Bertrand Russell, Fundamentos de filosofia (Barcelona: Penguin Random House, 2016).

44. Ricardo Guibourg, Derecho, sistema y realidad (Buenos Aires: Astrea, 2015). 
mizarlo a su dimensión meramente argumentativa ${ }^{45}$ que se caracteriza por su subjetividad y por ofrecer soluciones caso a caso. Claramente, la Escuela del derecho libre, el método de ponderación y el desmembramiento de las teorías de la argumentación jurídica dan cuenta de ello.

El derecho se ha caracterizado desde marcos de pensamiento político, ético y estético europeos, cabe entonces regresar los ojos hacia Latinoamérica, en la que tradicionalmente también se ha seguido un libreto eurocéntrico, pero que a partir de las reformas constitucionales de fines del siglo XX e inicios del XXI empieza a plantearse una visión que partiendo desde la superestructura jurídica, pretende descender a la infraestructura de la producción y de la vida cotidiana, aunque con furiosas resistencias desde las orillas ortodoxas del pensamiento jurídico.

Desde la visión infraestructural, Marx diferenció entre el valor de uso y el valor de cambio de los bienes convertidos en mercancías. Retomamos estas categorías, dado su valor explicativo sobre nuestra época, y por contener la clave para superarla. El valor de uso consiste en la utilidad de los objetos para garantizarnos la satisfacción de necesidades naturales. Una cosa vale según la cantidad de trabajo que se invierte en producirla y por su eficacia en la consecución del objetivo que motivó su confección. El valor de cambio es el precio que asigna el mercado según las manipulables leyes de la oferta y la demanda, independientemente de su utilidad y del servicio real que presten.

Para Heidegger, ${ }^{46}$ el siglo XX se caracteriza por un intercambio irracional entre las posiciones de medios y fines. En estado de arrojo en el mundo, el ser humano usa objetos para desarrollar su proyecto existencial. No obstante, por medios técnicos se ha maximizado la producción de bienes sin más fines que la acumulación del capital. Así, los entes han dejado de ser un medio para convertirse en un fin que contiene al ser. Trabajamos para consumir, acuñamos más planes de endeudamiento que de vida porque la sobreproducción de bienes desechables y superfluos generan estatus; y con ello, exclusión social y resistencia.

La promesa de dominio sobre la naturaleza desencadenó un modelo depredador de los recursos naturales, mediante la aplicación técnica del conocimiento científico. $\mathrm{La}$ lucha por las materias primas y la apertura de nuevos mercados para colocar los bienes no absorbidos por el mercado interno es la llave para mantener un modelo irresponsable de consumo, que constituye el germen de los actuales conflictos armados. Las

45. Manuel Atienza, El Derecho como argumentación (Barcelona: Ariel, 1999).

46. Martin Heidegger, El ser y el tiempo (México D. F.: Fondo de Cultura Económica, 2014). 
armas, que son un negocio, permiten entrar en control de territorios para extraer sus recursos naturales e incorporarlos a cadenas globales de producción.

El desencantamiento del mundo devino en un individualismo hedonista que desarticula el tejido social mediante una competencia narcisista que alimenta al mercado, según la clave de la fama y la fortuna. Según Lyotard, ${ }^{47}$ la posmodernidad constituye el fin de los grandes relatos filosóficos, proyectados al arte y al derecho. El individualismo existencial generó estilos estéticos que priorizan la subjetividad individual como el arte conceptual, abstracto y surrealista que sobreponen al yo frente al todo. No obstante, la mercantilización artística desembocó en el predominio del valor de cambio que introdujo la técnica y la masificación de la obra de arte, hasta su consecuente degradación y pérdida de su valor cúltico. ${ }^{48}$

Resulta mercantilmente ingenuo entregarse por años a componer una sinfonía, un mural, una escultura, una pieza operística o una obra literaria; cuando lo económicamente rentable está en escribir letras burdas con ritmos repetitivos, telenovelas cursis, tomar fotografías y publicar basura de rápida confección y fácil consumo en masa. Para Marcuse el arte ha muerto porque ha dejado de ser para sí, convirtiéndose en un medio de exhibición en el mercado. ${ }^{49}$

El arte irrumpe en la posmodernidad como una industria. La publicidad y la entrega de los premios Óscar, Nobel o Grammy son una forma de condicionar el consumo de lo que la misma industria vende. ${ }^{50}$ La industria del arte es un negocio que se autoalimenta mediante la publicidad y la moda que crea patrones de consumo. Hollywood, por medio del cine muestra un paradigma de éxito. Así, la cultura de masas homologa gustos, hábitos, creencias y valores, haciéndolas aparecer universales; invitándonos a formar parte del "progreso". La cultura de masas ha cambiado el arte por el entretenimiento, que es una efectiva manera para dejar de pensar y cuestionarnos sobre la

47. Jean-François Lyotard, La condición postmoderna (Buenos Aires: Planeta, 1990).

48. Walter Benjamin, La obra de arte en la era de su reproductibilidad técnica y otros escritos (Buenos Aires: Godot, 2012).

49. Gianni Vattimo, El fin de la modernidad (Barcelona: Gedisa, 2007), 47-98.

50. Debe llamar nuestra atención que los seis premios Nobel de literatura latinoamericanos (Gabriela Mistral, en 1945; Miguel Ángel Asturias, en 1967; Pablo Neruda, en 1971; Gabriel García Márquez, en 1982; Octavio Paz, en 1990; y Mario Vargas Llosa, en 2010) vivieron períodos extensos en el exterior, aunque escribieron sobre las problemáticas de sus lugares de origen. Todos vivieron en Francia, todos se vincularon a actividades políticas, especialmente al servicio exterior; y salvo el caso de Vargas Llosa, compaginaron con ideologías de izquierda. Estos patrones son más que una coincidencia, se trata de latinoamericanos que vieron a sus tierras con ojos europeos, describiendo una cultura folclórica, mágica, exótica que conquistó el paladar de la Academia Sueca. Esta fue la razón por la que Jean-Paul Sartre rechazó el premio en 1964. 
podredumbre de nuestra época. Por el contrario, se nos insta al sacrificio y a soportar la penurias presentes, a la espera de un final feliz.

La homologación de gustos y estándares son mecanismos de sujeción y control del centro sobre la periferia. El dominio cultural se traduce en dominio económico y jurídico, en términos de tratados de comercio y gasto que alimenta la industria. El derecho tampoco escapa al sensacionalismo que hace del proceso judicial un show en vivo, difundido por redes sociales y medios de comunicación que afectan la independencia del sistema judicial; y que encuentra en el neoconstitucionalismo su manifestación jurídica, puesto que las soluciones normativas no son las predeterminadas sino aquellas que se construyen sobre la marcha por tribunales cuyo marco legítimo de intervención es cada vez más indeterminado.

Para Carlos Bernal Pulido, las características del neoconstitucionalismo son: constitución material, omnipresente, principialista y garantizada judicialmente, por un modelo argumentativo basado en la ponderación. Estos elementos, nada nuevos, predominan en nuestra época. Junto al fin de los grandes relatos, que definen el arte y el nihilismo filosófico posmoderno; con el constitucionalismo posmoderno, el derecho dejó de pensar en sistemas completos que aspiran explicar la totalidad de la disciplina. Contrariamente, el neoconstitucionalismo dejó en manos del juez la resolución personalizada de casos. Por medio de la ponderación, el juez puede crear a discreción lagunas mediante interpretación a-contrario del texto legal o cubrirlas por medio del uso de la analogía o integración de derechos y principios implícitos. ${ }^{51} \mathrm{El}$ juez puede establecer la inaplicabilidad de la ley, y al verse liberado del legislador, lo suple para crear reglas a su arbitrio.

Para resolver el caso aplicando ponderación, ${ }^{52}$ el juez acude a principios jurídicos, que cuentan con un mismo peso abstracto; $\mathrm{y}$, como tal, requieren de un juez que establezca, a su leal saber y entender qué principio gozará de mayor peso concreto. Así, el juez construye, a conveniencia, una red argumentativa que justifique una decisión preconcebida. No obstante, el giro lingüístico del derecho en el siglo XX, prioriza el manejo de herramientas argumentativas que le permiten al juez, bajo un mismo caso, llegar a decisiones contrarias al priorizar el procedimiento más que el resultado.

51. El razonamiento a-contrario, se contrapone a la analogía. En esta, se establecen coincidencias sustanciales para extender el espectro normativo hacia casos no previstos; en el razonamiento a-contrario, se establecen diferencias sustanciales, que impedirían aplicar el precepto a un caso aparentemente similar. Nelson Barros Cantillo, Las nuevas herramientas de la argumentación jurídica (Bogotá: Gustavo Ibáñez, 2005), 77-98.

52. Juan Antonio García Amado, Iusmoralismo(s) (Lima: Legisprudencia, 2014). 
No podemos obviar el hecho por el cual los jueces constituyen una élite dedicada a defender los valores e intereses de grupos dominantes ${ }^{53}$ La reproducción del poder de sectores oligárquicos queda confiada a la misma élite, que nombra a sus jueces como garantes del sistema y portadores del dominio simbólico que reproducen jueces y abogados, formados para el efecto. El derecho, por medio del lenguaje y la institucionalidad, está facultado para nombrar y juzgar. En paralelo, la crítica del gusto separa lo bello, lo feo y lo sublime, adquiriendo relevancia política mediante su socialización. Igualmente, la moralidad dominante crea el delito, el pecado, tendiendo un puente entre lo ético y lo estético, lo bueno y lo malo, lo jurídico y lo antijurídico.

La toga, la sotana, los templos barrocos, los neoclásicos palacios de justicia, la Biblia, la Constitución, el teatro y el noticiero configuran una estética del poder y un imaginario de la realidad, creada retórica y mediáticamente para encubrir el dominio del espacio inmaterial por parte de la élite que autolegitima su posición; y su omnipresencia material e inmaterial. La política se degrada porque la disputa electoral se agota en eslóganes, sonrisas prefabricadas y promesas demagógicas que convierten a ciudadanos en clientes, y al juez en aval del pensamiento jurídico dominante.

Desde los estudios de la cultura, el filósofo riobambeño Bolívar Echeverría desarrolló el concepto de ethos barroco, categoría que permite comprender las dinámicas de nuestra cultura mestiza y nuestra ideología manifiesta en el arte, que como expresión social y política se ha visto reflejada en el surgimiento de un nuevo derecho. En América Latina, el ethos barroco se gestó entre las clases bajas y marginales de las ciudades mestizas del siglo XVII y XVIII, en torno a la vida económica informal y transgresora que llegó a tener mayor importancia que la economía formal, consagrada por las coronas ibéricas.

La cultura popular latinoamericana consistió en la indigenización de la cultura europea y la europeización de la cultura nativa, lo que generó una síntesis surgida de tesis contrapuestas; por ello, América Latina nunca fue moderna, sino popular; y como tal no podría ser posmoderna, sino transmoderna. Para Dussel,,${ }^{54}$ una cultura transmoderna es la que asume sin rechazo los elementos de la modernidad, pero los transforma al evaluarlos y al incorporarle elementos propios que la transfiguran. Esta incorporación portadora de una pluridiversidad multidimensional nace de un diálogo intercultural, que entrelaza múltiples modernidades como la latinoamericana, árabe,

53. Los sistemas contemporáneos adolecen de las características de los tres modelos corruptos de gobierno, según Aristóteles. La dictadura y la demagogia se encarnan en los liderazgos populistas del presidente de la República; la oligarquía descansa en jueces elegidos como cuotas políticas; y la democracia se mantiene por una asamblea legislativa que subordinan la razón y los intereses de todos, al número de votos y capacidad de maniobra. Aristóteles, La política (Madrid: Siglo XXI Editores, 2000), Libro IV.

54. Enrique Dussel, Filosofias del sur: descolonización y transmodernidad (Buenos Aires: Akal, 2015). 
hindú, china, islámica, ${ }^{55} \mathrm{y}$ otras; las mismas que no dejan de ser modernas por el solo hecho de no seguir el canon eurocéntrico.

Tradicionalmente, el arte latinoamericano no tuvo cabida en los teatros, en imprentas ni en galerías, porque su origen no corresponde a las élites; el arte popular se abrió paso por medio de la fiesta, que además de alegría y colorido, tiene significación ritual y política, a la vez que encarna una posición de rebeldía y resistencia. Así, el arte latinoamericano tiene un valor de uso cúltico, y como tal político, que vio la luz en la plaza pública donde se escenifica la teatralidad de la vida barroca del indio que debe parecer europeo, para no ser mentalmente colonizado. El Carnaval de la Sierra, la Mama Negra, la Diablada de Píllaro, los Pases del Niño, los toros de pueblo, los pregones, las procesiones, el Paseo del Chagra, y tantas otras piezas de nuestro patrimonio intangible, mezclan música, danza, teatro, escultura religiosa, símbolos culturales, disfraces y la exuberancia que hacen de la fiesta popular una obra de arte viva, holística, que trastoca todo el orden social, ${ }^{56}$ reconciliándose en su ambigüedad lo profano y lo sagrado.

En los años treinta del siglo XX, la literatura latinoamericano acompañó la problemática social. El realismo social con obras como Huasipungo de Jorge Icaza en Ecuador, El mundo es ancho y ajeno de Ciro Alegría en Perú, Raza de Bronce de Alcides Arguedas en Bolivia y otros, constituyen una denuncia de la miseria de las clases populares, que también es tema central del cine latinoamericano y del constitucionalismo social del siglo XX, plasmado originalmente en la Constitución mexicana de Querétaro de 1917 y su consonancia en la Constitución ecuatoriana de 1929. Así, las artes y el pensamiento político-jurídico, aun cuando cuente con autores prominentes y líderes caudillistas, debe entendérselas como superestructuras colectivas que trascienden la visión de autor.

El constitucionalismo latinoamericano transmoderno no rechaza al constitucionalismo clásico, pero incorpora elementos rescatados de su vertiente cultural indígena, concediéndole fisonomía propia y distinta del constitucionalismo inglés, estadounidense y francés que inspiraron los cimientos de la vida republicana. Esta identidad ha sido incorporada bajo el marco concepto de Sumak Kawsay en Ecuador y Sumak Qamaña en Bolivia y que constituyen la célula madre del nuevo constitucionalismo

55. Las culturas no europeas ni estadounidenses utilizan la receta del ángel de la historia para crear su propia modernidad. En el islam contemporáneo (Zizek 2015) se observa la utilización de instrumentos tecnológicos desarrollados por occidente, no para copiarlo, sino para liberarse de su opresión. La posmodernidad musulmana mira para atrás para encontrar los cimientos de su cultura y regresar históricamente hacia la constitución de un califato, que no será el mismo del siglo VI, sino uno renovado, tecnológico, radical, pero fiel a su esencia.

56. Bolívar Echeverría, Definición de la cultura (México D. F.: Era, 2001), 199-226. 
latinoamericano; cuya sofisticación es tal, que su práctica, contribuiría a superar los desafíos de la supuesta posmodernidad.

Para algunos juristas latinoamericanos, ${ }^{57}$ esta versión latinoamericana del constitucionalismo se caracterizaría por: a) un predominio de la democracia participativa, que no separa a electores de autoridades, sino que produce ciudadanos gestores y fiscalizadores de la actividad pública; b) un énfasis en la protección de derechos colectivos y sociales, que supera la idea del Estado raquítico impotente ante poderes fácticos; c) modelos cooperativos de producción, que elimina luchas entre obreros y empresarios porque la propiedad de los medios de producción es compartida por las personas que aportan la fuerza de trabajo y participan de los beneficios; d) relación armónica con la naturaleza, respetando sus ciclos vitales, como consumo para la satisfacción de necesidades naturales; e) reemplazo de la masa por sujetos colectivos organizados; f) propiedad pública de los sectores estratégicos y los recursos naturales; g) plurinacionalidad dialogante en igualdad de condiciones; h) pluralismo jurídico; i) Modelo de desarrollo basado en el Sumak Kawsay / Qamaña, que propone una visión holística de interacción armónica entre el individuo, el otro, la sociedad y la naturaleza, como un marco óptimo para mejorar las condiciones de vida. Este círculo se cierra con el factor más importante; j) la eliminación de las brechas sociales mediante la eliminación de privilegios y prácticas discriminatorias.

No ha de sorprender que la ortodoxia tilde a esta corriente de novelería populista, por romper el molde canónico del constitucionalismo moderno. No obstante, para nosotros se trata de la constitucionalización de nuestro sino popular para asumir su historia, enaltecer sus vertientes culturales para alcanzar autoconciencia de sí; y a partir de allí labrar su propio futuro. El constitucionalismo andino transmoderno no destruye, no desconoce los principios fundamentales del constitucionalismo clásico, ni rechaza los saberes ancestrales; de su condición sincrética barroca, popular y mestiza elabora un pensamiento renovado, complejo, plurinacional y relacional, cuya vigencia material ha de construirse con diálogo respetuoso, mente abierta y compromiso social.

57. Ramiro Ávila, El constitucionalismo andino (Quito: Universidad Andina Simón Bolívar, Sede Ecuador, 2016); Roberto Gargarella, "El nuevo constitucionalismo latinoamericano", Revista Estudios Sociales, año XXV, n. ${ }^{\circ} 48$ (2015); y Alejandro Medici, "Teoría constitucional y giro descolonial: narrativas y simbolismo de la Constitución. Reflexiones a propósito de la experiencia de Bolivia y Ecuador" (Lima: Tribunal Constitucional, 2011). 


\section{CONCLUSIONES}

El derecho, como cualquier otra superestructura, está condicionado por poderes hegemónicos en lo social y económico, cuya posición de privilegio le permite imponer sistemas éticos y estéticos que alcanzan dimensión política y respaldo institucional por medio de su juridicidad.

La historia de la filosofía, del arte y de las escuelas de pensamiento jurídico dominantes en distintos períodos, nos permite establecer un paralelismo cuyas coincidencias pueden ser explicadas a través de la hegemonía discursiva que, al apoderarse del espectro simbólico de la sociedad, redefine la configuración de este artificio que creamos para nosotros y que llamamos mundo.

El derecho como ciencia aplicable se encuentra en una crisis que coincide con la banalización de los ideales modernos tanto en lo filosófico como artístico, llegando a niveles de individualismo llevados a un relativismo que resuelve casos adhoc, a partir de lo cual se complejiza la función de explicar teóricamente al derecho como un fenómeno multidimensional.

Ante la crisis descrita, el constitucionalismo andino ha tenido que buscar en su vertiente cultural indígena algunos elementos que, fiel a nuestra configuración barroca, no renuncia ni rechaza los principios del constitucionalismo clásico, pero incorpora elementos tan importantes que terminan por darle una fisonomía propia y distinta.

\section{BIBLIOGRAFÍA}

Adorno, Theodor. Ensayo sobre Wagner. Madrid: Akal, 2008.

Aristóteles. La Política. Madrid: Siglo XXI Editores, 2000.

Atienza, Manuel. El Derecho como Argumentación. Barcelona: Ariel, 1999.

-.Introducción al Derecho. México D. F.: Fontamara, 2007.

Ávila Santamaría, Ramiro. El constitucionalismo andino. Quito: Universidad Andina Simón Bolívar, 2016.

Barros Cantillo, Nelson. Las nuevas herramientas de la argumentación jurídica. Bogotá: Gustavo Ibáñez, 2005.

Benjamin, Walter. La obra de arte en la era de su reproductibilidad técnica y otros escritos. Buenos Aires: Godot, 2012.

Bodenheimer, Edgar. Teoría del derecho. México D. F.: Fondo de Cultura Económica, 2007.

Botero, Andrés, compilador. Filosofia del Derecho. Medellín: Universidad de Medellín, 2012.

Bunge, Mario. Filosofia política. Barcelona: Gedisa, 2009.

Cabanne, Pierre, Joaquín Soler y Marta Masafred. El Barroco. Barcelona: Larousse, 2007. 
Campanella, Tommaso. La ciudad del sol. México D. F.: Grupo Editorial Tomo, 2015.

Cherne, Diana. La creencia y el psicoanálisis. México D. F.: Fondo de Cultura Económica, 2006.

D’Hondt, Jacques. De Hegel a Marx. Buenos Aires: Amorrortu, 1972.

Dussel, Enrique. Filosofías del sur: descolonización y transmodernidad. Buenos Aires: Akal, 2015.

Echeverría, Bolívar. Definición de la cultura. México: Era, 2001.

-. Modernidad y Blanquitud. México D. F.: Era, 2010.

Foucault, Michel. Las palabras y las cosas. Buenos Aires: Siglo XXI Editores, 1968.

Freud, Sigmund. Esquema de psicoanálisis. Madrid: Alianza Editorial, 2016.

Fromm, Erich. Ética y política. Barcelona: Paidós, 2004.

García Amado, Juan. Iusmoralismo(s). Lima: Legisprudencia, 2014.

García Maynez, Eduardo. Introducción a la lógica jurídica. México D. F.: Fontamara, 2010.

Gargarella, Roberto. "El nuevo constitucionalismo latinoamericano”. Revista Estudios Sociales, año XXV, n. ${ }^{\circ} 48$ (2015): 169-73.

Gombrich, E. H. La historia del arte. Nueva York: Phaidon, 2014.

Guibourg, Ricardo. Derecho, sistema y realidad. Buenos Aires: Astrea, 2015.

Habermas, Jürgen. Teoría de la acción comunicativa. Madrid: Cátedra, 1994.

Hegel, G. W. F. Fenomenología del espíritu. México D. F.: Fondo de Cultura Económica, 2015.

Heidegger, Martin. El ser y el tiempo. México D. F.: Fondo de Cultura Económica, 2014.

Horkheimer, Max, y Theodor Adorno. Dialéctica de la Ilustración. Madrid: Trotta, 2006.

Husserl, Edmund. Fenomenología de la conciencia inmanente del tiempo. Buenos Aires: Prometeo, 2014.

Kant, Immanuel. Crítica del juicio. Buenos Aires: Biblioteca Universal, 2003.

Kelsen, Hans. Teoría pura del derecho. Buenos Aires: Eudeba, 2000.

Locke, John. Segundo Tratado sobre el Gobierno Civil. Buenos Aires: Alianza Editorial, 1998.

Lyotard, Jean-François. La condición postmoderna. Buenos Aires: Planeta, 1990.

Medici, Alejandro. "Teoría constitucional y giro descolonial: narrativas y simbolismo de la Constitución. Reflexiones a propósito de la experiencia de Bolivia y Ecuador”. Lima: Tribunal Constitucional, 2011.

Nietzsche, Friedrich. Asi habló Zaratustra. Madrid: Edimat, 2007.

—. El nacimiento de la tragedia. México D. F.: Grupo Editorial Tomo, 2014.

Pascual Esteban, Jesús Antonio. Historia de la Filosofía. Barcelona: Marenostrum, 2008.

Robinet, André. El pensamiento europeo de Descartes a Kant. México D. F.: Fondo de Cultura Económica, 2014.

Ross, Alf. Sobre el derecho y la justicia. Buenos Aires: Eudeba, 2011. 
Russell, Bertrand. Fundamentos de Filosofia. Barcelona: Penguin Random House, 2016.

Sánchez-Albornoz, Nicolás. Historia mínima de la población de América Latina. México D. F.: Turner, 2014.

Sánchez, Cristina. Estar (políticamente) en el mundo. Madrid: Batiscafo, 2015.

Sartre, Jean-Paul. Reflexiones sobre la cuestión judía. Buenos Aires: Penguin Randon House, 2015.

Schmitt, Carl. La tiranía de los valores. Buenos Aires: Hydra, 2012.

Schopenhauer, Arthur. El mundo como voluntad y representación. Madrid: Alianza Editorial, 2015.

Todorov, Tzventan. El espiritu de la Ilustración. Barcelona: Galaxia Gutenberg, 2008.

Vattimo, Gianni. El fin de la modernidad. Barcelona: Gedisa, 2007.

Vilar, Gerard. "Ética y estética”. En Estética, editado por Francisca Pérez. Madrid: Tecnos, 2013. 